\title{
Perceived Trustworthiness of Knowledge Sources: The Moderating Impact of Relationship Length
}

\author{
Daniel Z. Levin \\ Rutgers University
}

\author{
Ellen M. Whitener and Rob Cross \\ University of Virginia
}

\begin{abstract}
Prior meta-analytic evidence has indicated no association between relationship length and perceived trustworthiness. Viewing trustors as information processors, the authors propose a model in which relationship length, although having no direct effect on perceived trustworthiness, moderates the association between perceived trustworthiness and the basis on which people decide to trust each other. Specifically, as trustors learn about others, they base their trust on different kinds of information (demographic similarity, trustworthy behavior, and shared perspective). Hierarchical multiple regression analyses of a field survey of supervisors and subordinates from 3 companies $(N=88)$ provide evidence consistent with this prediction: Perceived trustworthiness is associated with demographic similarity in newer relationships, with trustworthy behavior in relationships that are neither brand new nor old but in-between, and with shared perspective in older relationships.
\end{abstract}

Keywords: trust, relationship length, information processing

Trust is often described as a willingness to be vulnerable on the basis of positive expectations of others (Butler, 1991; Lewicki \& Bunker, 1996; Mayer, Davis, \& Schoorman, 1995; Rousseau, Sitkin, Burt, \& Camerer, 1998). It has numerous documented benefits, such as job satisfaction, organizational commitment, citizenship behavior, cooperation, learning, and knowledge sharing (e.g., Dirks \& Ferrin, 2002; Levin \& Cross, 2004; McAllister, 1995). Given these benefits, an important research question is determining the information that people rely on when making a decision to trust others at work. To that end, there is a growing body of work exploring antecedents to trust (Dirks \& Ferrin, 2002).

Some theorists have proposed that trust is affected by relationship length (e.g., Blau, 1964; Lewicki \& Bunker, 1996): As two people interact and learn about each other, their relationship matures and trust grows. Surprisingly, little work has tested this idea.

Daniel Z. Levin, Management and Global Business Department, Rutgers Business School-Newark and New Brunswick, Rutgers University; Ellen M. Whitener and Rob Cross, McIntire School of Commerce, University of Virginia.

Ellen M. Whitener passed away in March 2005.

An earlier and abbreviated version of this article appeared in the 2004 Best Papers Proceedings of the Academy of Management and was presented at the August 2004 Academy of Management annual meeting, New Orleans, Louisiana. We thank the following people for their input on previous versions of this article: Matthew Agin, Tom Bateman, Susan Brodt, Chao Chen, Don Ferrin, Michael Johnson-Cramer, Terri Kurtzberg, and Patrick Saparito. We appreciate the support of Rutgers University's Technology Management Research Center and the McIntire School of Commerce Foundation.

Correspondence concerning this article should be addressed to Daniel Z. Levin, Management and Global Business Department, Rutgers Business School-Newark and New Brunswick, Rutgers University, 111 Washington Street, Newark, NJ 07102. E-mail: levin@business.rutgers.edu
In a recent meta-analysis on trust in leadership, fewer than 5\% of the studies (5 of 106 independent samples) measured relationship length (Dirks \& Ferrin, 2002), and the results of those studies did not support this idea. The average corrected correlation between trust and relationship length was - -01 , suggesting that trust does not necessarily increase over the course of a relationship.

This finding makes sense for several reasons. First, even at the start of a relationship, trust can be high (or low), owing to the use of cognitive cues derived from group membership or stereotypes (Kim, Ferrin, Cooper, \& Dirks, 2004; McKnight, Cummings, \& Chervany, 1998; Meyerson, Weick, \& Kramer, 1996). Second, as relationship length increases and individuals observe another's behavior, they may conclude that the person is either trustworthy or untrustworthy (Dirks \& Ferrin, 2002). That is, as the relationship matures and people learn more about each other, the bases on which someone decides to trust another will likely shift. In the brand new relationship, the most salient cues available will be observable features of that person. As one begins to form expectations of someone, information such as whether the person is the same gender or age will be attended to and filtered by one's existing knowledge of these categories. However, the influence of group categories on attention and comprehension (e.g., stereotyping) should lessen with time as one observes another and begins to infer intentions and make attributions on the basis of that person's behaviors. Finally, as one abstracts specific behavioral observations into general representations, one likely focuses more on overall perceptions of a person and less on behaviors in isolation from beliefs formed about that person.

In this article we explore the possibility that people base their trust of someone on different kinds of information depending on how long they have known the other person. Specifically, we propose that trustors are information processors and that relationship length moderates the relative strength of the association between trust and these bases of trust. 


\section{Concepts of Trust}

Trust refers to the willingness of parties to accept risk and be vulnerable to others (Mayer et al., 1995). This willingness to be vulnerable derives from the party's perceptions of the other's trustworthiness. Three factors appear to be most commonly related to these perceptions: perceptions of the other's ability, integrity, and benevolence (Davis, Schoorman, Mayer, \& Tan, 2000; Mayer et al., 1995). Perceived ability refers to the trustor's belief that the other party can accomplish the specific task at hand; perceived integrity refers to the trustor's belief that the other party is committed to an acceptable set of principles; and perceived benevolence refers to the trustor's belief that the other party cares for him or her and has his or her best interests at heart. All three trustworthiness perceptions are significantly related to trust (Davis et al., 2000).

We focus more specifically on individuals' perceptions of the other's benevolence, because this is a fundamental element of an interpersonal relationship. Unlike ability and integrity, which are mainly characteristics of the individual trustee that would not be expected to vary much across the trustee's different relationships, benevolence is typically a function of a specific relationship, which is our focus. In this context, perceived trustworthiness represents a person's willingness to be vulnerable to another because he or she expects that the other person has his or her interests at heart, cares for him or her, and feels goodwill toward him or her.

\section{Bases of Trust}

Previous research indicates that trust, especially the benevolence dimension, may be built on three different bases. First, an extension of social identity theory suggests trust may be built on perceived demographic similarities. Hogg and Terry (2000) posited that individuals are motivated to reduce uncertainty and establish their similarity and difference with others to enhance selfesteem and self-identity. As a result, individuals engage in processes of social comparison to confirm their distinctiveness, value, and self-worth. Prototypes play a critical role in this social comparison process: "Prototypes [cognitive representations of a group's defining features] embody all attributes that characterize groups and distinguish them from other groups, including beliefs, attitudes, feelings, and behaviors" (Hogg \& Terry, 2000, pp. 123124). This process focuses on the prototypical features of the group (e.g., a team or a category of individuals) to maximize similarities within the group and differences with other groups.

The prototype may be rooted in demographic similarity in which individuals may not interact as "unique individuals, but rather as embodiments of the relevant prototype-a process of depersonalization" (Hogg \& Terry, 2000, p. 123). Thus, people's commitment and attraction to the group are rooted in impersonal prototypical feelings, attitudes, and so forth associated with that group. As Chatman and Flynn (2001) noted, "People often use immediately apparent physical features, such as race, sex, and national origin, to categorize others and predict their behavior" (p. 957). Moreover, people believe that demographically similar others are more honest, trustworthy, and cooperative (Brewer, 1979; McAllister, 1995; Shore, Cleveland, \& Goldberg, 2003; Tsui \&
O'Reilly, 1989). Individuals may thus "adopt a sort of 'depersonalized trust' based on category membership alone" (Brewer, 1981, p. 356), such as same age or gender.

Second, Blau's (1964) perspective on social exchange suggests that trust grows as people interact, interpret each other's behavior, and reciprocate. Drawing on this notion, others have proposed that trust is built on perceptions of behaviors such as open two-way communication, discretion, availability, reliability, and consistency (e.g., Butler, 1991; Dirks \& Ferrin, 2002; Korsgaard, Brodt, \& Whitener, 2002; Mayer et al., 1995; Simons, 2002; Whitener, Brodt, Korsgaard, \& Werner, 1998).

Third, trust may also be rooted in shared perspectives. Here the features of attraction are not those associated with the depersonalized prototypes of a group but rather the personalized expectations and beliefs about a specific, known individual (Hogg \& Terry, 2000). Individuals develop expectations derived from their observations and interactions. People observe others' behavior; identify their underlying outlooks, needs, choices, and preferences (Lewicki \& Bunker, 1996); and base their expectations on the extent to which they share the same goals, perspective, and identity. Evidence suggests that people exhibit greater trust in those they perceive as having similar outlooks and goals (e.g., McAllister, 1995; Sitkin \& Roth, 1993; Tsai \& Ghoshal, 1998).

\section{The Interaction of Relationship Length With Bases of Trust}

We believe relationship length may change the relative importance of these three bases of trust. Specifically, we propose that the association among relationship length, bases of trust, and trust can be explored by viewing the trustor as an information processor and trust as the output of an information-processing system. Although models of information processing vary in their details, they reflect the same basic flow: "information is input from the environment, processed and stored in memory, and output in the form of some learned capability" (Driscoll, 2005, p. 74). New information is "processed"- that is, perceived, interpreted, and given meaningusing preexisting categorical representations (Bobrow \& Norman, 1975; Reicher, 1969; Rumelhart, 1984; Rumelhart \& McClelland, 1981). These preexisting meaning structures, often called schemas, allow people to conserve cognitive resources. They also reflect individuals' organized and generalized knowledge and expectations about their observations and experiences (Neath, 1998).

Perceptions of trustworthiness can be a product of observations of others that become transformed into symbolic representations that guide expectations and action (Bandura, 1986; Ferrin \& Dirks, 2003). Demographic and behavioral observations are the information that trustors attend to, examine for patterns, and compare with existing schemas. In brand new relationships, trustors must rely on demographic information. Without additional information to consider, trustors in newer relationships are more likely to process demographic information using group-based schemas, basing their trust on the similarity of group membership. As Meyerson et al. (1996) stated, "Expectations defined in terms of categories are especially likely because people have little time to size up one another" (p. 174). As the relationship continues, trustors also observe behavior, processing this information against existing schemas to either support or disconfirm inferences based on group 
prototypes. Thus, as individuals interpret their observations vis-àvis the original prototype associated with demographic membership, they increasingly base their trust less on demographic similarity and more on the information they are processing from their observations of another's trustworthy behavior. More nuanced schemas based on behavioral exemplars are then invoked. The accumulation of behavioral observations and related schemas, however, will at some point begin to be abstracted into a representation of that person and lead one to base trust less on specific behaviors such as openness and discretion and more on inferences of personal commonality or shared perspective. Specific behaviors become interpreted, processed, and comprehended in the context of many accumulated experiences. The decision to trust is then influenced more by this individualized schema of the other person and less by observations of specific behaviors.

In summary, an information-processing perspective on trust suggests that the decision to trust is made on different bases as relationship length increases. The newer the relationship is, the more likely it is that trustors will have only demographic information and so will base trust on the extent to which they assume they share an understanding of the world because of demographic similarity. When relationship length grows, trustors also have behavioral information, which they start to emphasize over demographic categories. Finally, as a relationship continues, the increasing volume of information about the other person gets organized into an individualized schema associated with shared perspective, which becomes more strongly associated with trust than specific behaviors. Thus we propose the following:

Hypothesis 1: Relationship length will moderate the positive association between demographic similarity-that is, same age (Hypothesis 1A) and same gender (Hypothesis 1B) - and level of trust such that the newer the relationship is, the stronger the association will be.

Hypothesis 2: Relationship length will moderate the positive association between trustworthy behaviors and level of trust such that the association will be stronger for intermediate relationships and weaker for newer or older relationships.

Hypothesis 3: Relationship length will moderate the positive association between shared perspective and level of trust such that the older the relationship is, the stronger the association will be.

We test these hypotheses in the context of knowledge seeking with a sample of managers and subordinates. In general, individuals who ask for and rely on information from others may find themselves in vulnerable positions, perhaps receiving inaccurate information, not receiving it in a timely fashion, or having their own ignorance exposed. This vulnerability increases when the knowledge source is a supervisor or subordinate. For example, admitting one's ignorance to a subordinate could undermine one's authority, and admitting one's ignorance to a supervisor could lead to lower performance evaluations. Thus, dependence and vulnerability are likely to be high when there are direct reporting relationships, thereby making the issue of trust particularly salient. Moreover, subordinates and supervisors cannot always choose or easily sever their vertical relationships, and so vulnerability is especially acute in these relations.

\section{Method}

\section{Procedures}

This study's data were collected as part of an ongoing and larger program of research focused on the role of trust in the knowledge-seeking context (e.g., Abrams, Cross, Lesser, \& Levin, 2003; Levin \& Cross, 2004). The cross-sectional survey data came from employees working in a division of a U.S. pharmaceutical company, British bank, or Canadian oil and gas company. All three divisions were engaged in knowledge-intensive work (research and development, financial modeling, and oil exploration) in which one would anticipate a reliance on others for information. We pursued three different industries and countries to increase the generalizability of the research. In a separate analysis, we determined that our results were consistent (i.e., did not differ significantly) across the three firms, $F(22,47)=0.74, p=.775$.

We conducted a pretest with 20 people (not affiliated with our three sample companies) before finalizing the survey. We then sent out a two-part survey in Microsoft Excel via e-mail attachment. To reduce social desirability bias, we promised respondents confidentiality and had them return their surveys directly to the researchers (Tsai \& Ghoshal, 1998). We used the following standard egocentric network survey techniques (e.g., Burt, 1992; Scott, 1990): First, respondents were instructed, "Consider a project that you are currently involved with or that ended recently (in the past three months) that you feel holds significance for your career." The median length of project involvement, for both ongoing and completed projects, was 6 months. Respondents then listed up to 10 or 15 people to whom they had turned for information or knowledge to get their work done on that project. To reduce sample bias, which might have occurred if we had asked for only the top advice givers, respondents chose from their full list the two most helpful and two least helpful knowledge sources for the project. This approach affects neither the slope nor the standard error of the regression lines, subject to the usual statistical assumptions for ordinary least squares (e.g., normality, constant variance); according to an analysis of residuals, these assumptions were not violated. For each of the four sources chosen, we next asked each respondent a set of questions (e.g., How much did you trust this person?).

As part of our larger program of research, we were interested in the role of trust at the moment when people first sought out a knowledge source for a given project; hence, we began all survey items with the phrase "Prior to seeking information/advice from this person on this project." For some respondents, this moment in time was when they first met a knowledge source, thereby allowing us to capture "brand new" relationships; for others, the knowledge source at that point was already well known to the respondent. One limitation of this design is that respondents may have had recall difficulties (e.g., faulty memory) or biases (e.g., basing responses on subsequent events). Although we cannot rule out these possibilities completely, we did try to minimize them. For example, to minimize retrospective bias, we instructed respondents to answer questions "to the best of your recollection, regardless of whether or not you had a prior relationship with this person." As stated above, we also continually reminded respondents of the relevant time frame at the beginning of every survey item. Further, by asking respondents to choose either a current or a recent project, we hoped to anchor them on something concrete and recent and thereby reduce recall problems. In a follow-up analysis, we found no significant differences in any of our hypothesized results between the $79 \%$ of respondents who chose an ongoing project and the $21 \%$ who chose a completed project, $F(11$, $58)=0.79, p=.652$. Similarly, in terms of the recall issue, we found no significant differences in our hypothesized results for respondents working on longer versus shorter projects, $F(11,58)=1.29, p=.251$. 
Common method bias can often be a problem in this type of survey research (Podsakoff, MacKenzie, Lee, \& Podsakoff, 2003); however, we believe that our results are not substantially inflated or affected, for several reasons. First, we split our survey into two halves and sent out the second half within a week after receiving the first half. This procedure has been found to reduce common method bias (Doty \& Glick, 1998; Morrison, 2002) by reducing the salience of contextually provided retrieval cues, the use of previous answers to fill in retrieval gaps, consistency motifs, and demand characteristics (Podsakoff et al., 2003). As a side benefit, this split also helped lessen the burden of the overall survey by creating two 20-30-min surveys instead of a more intimidating 40-60-min survey. Second, our analyses focused on interaction effects, another indicator that common method bias is less of a concern, because interaction effects demonstrate that respondents have not rated all items in a thoughtless manner as either high or low (Brockner, Siegel, Daly, Tyler, \& Martin, 1997). Third, our demographic and control variables were relatively objective and so were likely not compromised (Doty \& Glick, 1998).

\section{Sample}

We obtained an overall response rate of 48\%, with 40-45 respondents per firm, for an initial sample of 127. Our sample had no significant response bias for gender and office location, the two areas for which we had data on nonrespondents. As described above, respondents initially provided detailed data on four people each. For the current study, however, we were interested in independent responses in the manager-subordinate relationship, for the reasons described earlier. We therefore identified respondents who included supervisors and subordinates among their knowledge sources. If the respondent included only one subordinate or supervisor among his or her four knowledge sources, we then retained that set of responses in the sample. However, if the respondent described more than one subordinate or supervisor, then we randomly picked one, in order to maintain independence among the observations. This procedure yielded 92 individuals who responded about either their subordinate or their supervisor; listwise deletion of missing values further reduced our sample size to 88 . Within this final sample, most respondents were male $(66 \%)$, in their 30 s or 40 s $(73 \%)$, and college graduates $(63 \%)$. On average, respondents had worked in their division for 5.8 years; company, 10.7 years; and industry, 16.4 years.

\section{Measures}

To make sure none of our 18 perceptual items cross-loaded onto the wrong construct, we conducted a factor analysis: The scree plot of eigenvalues yielded seven factors (trust plus four trustworthy behaviors and two aspects of shared perspective). An unweighted least squares extraction with direct oblimin rotation indicated high discriminant validity, with all expected factor loadings above .37 and no cross-loadings above .29. For theoretical reasons, we later created composite scores for trustworthy behaviors and for shared perspective (see below). Internal consistency was high, with all Cronbach's alpha reliabilities above .70. Unless indicated otherwise, all items used a 7-point scale ranging from strongly disagree (1) to strongly agree (7).

Perceived trustworthiness. We measured perceptions of trustworthiness in terms of benevolence with three items (Johnson, Cullen, Sakano, \& Takenouchi, 1996): "Prior to seeking information/advice from this person on this project, I assumed that he or she would always look out for my interests"; ". . . I assumed that he or she would go out of his or her way to make sure I was not damaged or harmed"; and "... I felt like he or she cared what happened to me."

Demographic similarity. We measured "same gender" by asking respondents whether they were the same gender as the other person (coded as 1 ) or not (coded as 0 ). The results indicated that $68 \%$ of the dyads were the same gender, that is, $49 \%$ male-male plus $19 \%$ female-female. Because our results for "same gender" did not differ by gender, $F(3,68)=$ $0.13, p=.940$, we used this global measure of "same gender." We also asked whether the other person was the same age as the respondent within plus or minus 5 years (coded as 1 ) or older or younger by 5 or more years (coded as 0 ). (We were restricted by the companies from collecting racial identity data for legal reasons.)

Trustworthy behavior. We adapted nine items from Butler (1991) focused on the extent to which the knowledge source seemed open (e.g., "Prior to seeking information/advice from this person on this project, I assumed that this person would generally tell me what he or she was thinking"), discreet, receptive, and available. Because our theoretical interest was not in any one specific behavior, we followed Korsgaard et al. (2002) and created an average score for each of these four behaviors and then averaged these four scores to create a composite measure. Reliability based on the nine items was .83; based on the four average scores, .75 .

Shared perspective. We measured shared perspective as the composite of two constructs: shared language and shared vision. As a manifestation of shared perspective, parties develop a sense of the extent to which they share the same language or jargon, what Argyres (1999) called "a 'technical grammar' for communication" (p. 162). The three items for shared language measured the extent to which the knowledge receiver and source seemed on the same wavelength ("Prior to my seeking information/advice from this person on this project, it felt like we could communicate on the same "wavelength"'), understood each other, and used similar jargon and terminology. We also generated three items for shared vision, similar to those used in previous research (e.g., Tsai \& Ghoshal, 1998), to measure the extent to which a knowledge source and knowledge receiver (in the eyes of the receiver) shared goals, concerns, and purpose.

Relationship length. We asked respondents how long they had known the other person prior to seeking information or advice on the project. The raw responses ranged from 0 to 20 years $(M=4.5, S D=5.5)$. Following Currall and Judge (1995), we then calculated the logarithm of the number of months (plus 1) that the respondent reported having known the knowledge source. We applied this procedure for two reasons. First, log transformations better account for how people perceive the length of a relationship. For example, knowing someone an extra month after only a 1-month relationship is a much more important jump - that is, it "feels" like a bigger difference to people - than knowing someone an extra month after 10 years. Second, log transformations reduce skewness and make this type of variable more normally distributed. For our sample, a maximum-likelihood test for the Box-Cox power transformation showed that the maximum "normality" could be attained at $\lambda=0.14$, which is closest to a $\log$ transformation (Neter, Kutner, Nachtschiem, \& Wasserman, 1996, p. 133).

Overall, we measured trust, relationship length, and shared language in the first survey half. Same age, same gender, trustworthy behaviors, and shared vision were measured in the second half.

Control variables. We also measured respondent's age, on an 11-point scale with 5 -year age ranges: $1=24$ years old or younger, $2=25-29$ years old, and so forth, up until $11=70$ years old or older. Respondent's education was measured on a 5 -point scale: $1=$ high school, $2=$ some college, 3 = college (4-year degree), $4=$ master's, $5=$ doctorate Respondent's gender was coded 1 for male and 2 for female. To control for the direction of the relationship, we coded whether a knowledge source was the respondent's direct supervisor (1) or a subordinate (0). Finally, as previous research has shown that communication frequency affects trust (Becerra \& Gupta, 2003; Chattopadhyay, 1999; McAllister, 1995), we combined two items as a control. The first, adapted from Hansen (1999), asked how often the respondent had communicated with the source prior to seeking him or her out as a knowledge source on the project in question, from daily (1) to once every three months or less (or never) (7) $(M=5.53$, $S D=2.26$ ). A second item asked the extent to which the respondent had interacted with the knowledge source, from no extent (1) to to a very great 
extent (5) $(M=3.91, S D=1.24)$. To combine the different scales, we reverse coded the first item, normalized both, and then averaged them. In a follow-up analysis to rule out alternative explanations, we also tested seven other controls-same function, non-work-related friendship, company, ongoing versus completed project, respondent satisfaction with project outcomes, length of respondent's project involvement, perceived helpfulness (most vs. least) of knowledge source to respondent's work on the project-with no change in results.

\section{Analysis}

We analyzed the data using hierarchical multiple regression. To create interaction terms between our independent variables and relationship length, we mean-centered the variables before multiplying them. This procedure leaves each variable's standard deviation unchanged. It also reduces multicollinearity problems, which were minimal here, as all variance inflation factors in Table 2 were well below the standard cutoff of 10 . To test Hypothesis 2, we included a squared term and a squared term interaction (Aiken \& West, 1991). We used a significance level of .05 for all tests.

\section{Results}

Descriptive statistics and correlations are reported in Table 1; regression results, in Table 2 . Because standardized $(\beta)$ coefficients are not interpretable for interaction effects (Aiken \& West, 1991), we report the unstandardized (B) coefficients. As in previous research, the simple correlation between relationship length and perceived trustworthiness was nonsignificant.

As shown in Equation 3, Hypotheses 1B, 2, and 3 were supported; Hypothesis 1A was not. The interaction effect of same age with relationship length (Hypothesis 1A) was not statistically significant $(p=.739)$. The interaction effect of same gender with relationship length (Hypothesis 1B) was significant ( $p=.014)$; that is, as predicted by Hypothesis $1 \mathrm{~B}$, the newer the relationship was, the greater was the association between same gender and trust. As predicted by Hypothesis 2, the second-order interaction term (trustworthy behaviors times the square of relationship length) was negative and statistically significant ( $p=.026)$. This result indicates that the association of trustworthy behaviors with trust was greatest in relationships that were neither very new nor very old but in-between. Hypothesis 3 was also supported; that is, the older the relationship was, the greater was the association between shared perspective and trust $(p=.002)$.

To help illustrate the statistically significant interaction for Hypothesis 2, we graphed several simple slopes. First, we chose the relationship length where the association of trustworthy behaviors with trust was at its maximum. Following the procedures in Aiken and West (1991), we computed this relative maximum to be at a (mean centered) relationship length of -.74 , which turns out to be roughly one standard deviation below the mean and which translates to the respondent's having known the other person for about 3 months. For convenience, we labeled this an "intermediate" relationship and then also graphed two more simple slopes, on either side of this relative maximum: "brand new" relationships (0 months) and "old" relationships (one standard deviation above the mean, which, with the logarithm [Currall \& Judge, 1995], translates to about 9 years). For consistency and simplicity, we used the same three slopes to help illustrate Hypotheses 1B, 2, and 3 (see Figures 1, 2, and 3). These simple slopes serve to illustrate each interaction effect, but for interested readers, they can also be tested for statistical significance; note, however, that the only test for comparing simple slopes with each other is the relevant interaction term in Equation 3 (Aiken \& West, 1991). To highlight the curvilinear nature of the interaction for Hypothesis 2, we also graphed in Figure 4 the values of the simple slopes shown in Figure 2.

Finally, we note that the association between same age and trust was not statistically significant, regardless of relationship length. This null finding may be due to the operation of age-oriented norms, specifically the expectation that supervisors should be older than their subordinates (Chattopadhyay, 1999; Lawrence, 1988, 1996; Shore et al., 2003). We explored this possibility in a follow-up analysis and found that counternormative knowledge sources-those who were either younger supervisors or older subordinates ( $9.1 \%$ of our sample) — were trusted significantly less than normative (older supervisors or younger subordinates) or same-aged pairings $(p=.002)$. This result did not vary significantly by relationship length ( $p=.947)$. Thus, individuals tended

Table 1

Means, Standard Deviations, Correlations, and Internal Consistency Reliabilities

\begin{tabular}{|c|c|c|c|c|c|c|c|c|c|c|c|c|c|}
\hline Variable & $M$ & $S D$ & 1 & 2 & 3 & 4 & 5 & 6 & 7 & 8 & 9 & 10 & 11 \\
\hline 1. Perceived trustworthiness & 6.00 & 1.00 & $(.84)$ & & & & & & & & & & \\
\hline 2. Respondent's age & 5.22 & 1.61 & .06 & - & & & & & & & & & \\
\hline 3. Respondent's education & 2.97 & 1.16 & -.05 & -.04 & - & & & & & & & & \\
\hline 4. Respondent's gender & 1.34 & 0.48 & -.09 & .08 & .13 & - & & & & & & & \\
\hline 5. Supervisor (vs. subordinate) & 0.61 & 0.49 & -.01 & $-.47 * *$ & .12 & .03 & - & & & & & & \\
\hline 6. Communication frequency & -0.01 & 0.89 & $.24 *$ & .20 & .03 & $.26 *$ & .01 & $(.72)$ & & & & & \\
\hline 7. Relationship length ${ }^{\mathrm{a}}$ & 1.33 & 0.71 & .16 & .20 & $-.27 *$ & .00 & -.10 & $43^{* * *}$ & - & & & & \\
\hline 8. Same age ${ }^{\mathrm{a}}$ & 0.38 & 0.49 & -.02 & .06 & -.14 & .09 & .13 & -.12 & .02 & - & & & \\
\hline 9. Same gender ${ }^{\mathrm{a}}$ & 0.68 & 0.47 & .13 & .00 & .00 & -.18 & -.04 & -.21 & .00 & .08 & - & & \\
\hline 10. Trustworthy behaviors ${ }^{\mathrm{a}}$ & 6.08 & 0.69 & $.53 * *$ & $.25^{*}$ & -.03 & -.02 & $-.22 *$ & $.38 * *$ & $.31 * *$ & -.14 & .00 & $(.83)$ & \\
\hline 11. Shared perspective ${ }^{a}$ & 6.15 & 0.65 & $.55^{* *}$ & $.22 *$ & .05 & -.10 & $-.21 *$ & $.28^{* *}$ & $.21 *$ & -.05 & .15 & $.69^{* *}$ & $(.76)$ \\
\hline
\end{tabular}

Note. $N=88$. Tests for correlations are two tailed. Internal consistency reliabilities are presented along the diagonal in parentheses.

${ }^{a}$ Variable was subsequently mean centered (i.e., initial mean subtracted from each observation) for regression analyses in Table 2.

$* p<.05 . \quad * * p<.01$. 
Table 2

Regression Results for Perceived Trustworthiness

\begin{tabular}{|c|c|c|c|c|c|c|c|c|c|}
\hline \multirow[b]{2}{*}{ Variable } & \multicolumn{3}{|c|}{ Equation 1} & \multicolumn{3}{|c|}{ Equation 2} & \multicolumn{3}{|c|}{ Equation 3} \\
\hline & $B$ & $S E$ & $95 \% \mathrm{CI}$ & $B$ & $S E$ & $95 \% \mathrm{CI}$ & $B$ & $S E$ & $95 \% \mathrm{CI}$ \\
\hline (Constant) & $6.40 * * *$ & 0.59 & $5.23,7.56$ & $6.51 * * *$ & 0.50 & $5.52,7.50$ & $6.88 * * *$ & 0.48 & $5.92,7.85$ \\
\hline Respondent's age & 0.00 & 0.08 & $-0.16,0.16$ & -0.03 & 0.07 & $-0.16,0.11$ & -0.03 & 0.06 & $-0.16,0.09$ \\
\hline Respondent's education & -0.01 & 0.10 & $-0.21,0.19$ & -0.07 & 0.09 & $-0.24,0.11$ & -0.12 & 0.08 & $-0.29,0.05$ \\
\hline Respondent's gender & -0.32 & 0.24 & $-0.79,0.15$ & -0.11 & 0.21 & $-0.52,0.31$ & -0.23 & 0.20 & $-0.64,0.18$ \\
\hline Supervisor (vs. subordinate) & -0.01 & 0.25 & $-0.52,0.49$ & 0.23 & 0.23 & $-0.22,0.68$ & 0.24 & 0.21 & $-0.19,0.67$ \\
\hline Communication frequency & $0.32 *$ & 0.15 & $0.03,0.61$ & 0.11 & 0.14 & $-0.16,0.38$ & 0.22 & 0.13 & $-0.05,0.48$ \\
\hline Relationship length (RL) & 0.09 & 0.19 & $-0.29,0.46$ & -0.07 & 0.16 & $-0.40,0.25$ & 0.10 & 0.17 & $-0.23,0.43$ \\
\hline $\mathrm{RL}^{2}$ & 0.13 & 0.23 & $-0.33,0.60$ & -0.01 & 0.20 & $-0.42,0.40$ & 0.00 & 0.21 & $-0.43,0.43$ \\
\hline Same age & & & & 0.06 & 0.20 & $-0.34,0.46$ & 0.20 & 0.20 & $-0.19,0.59$ \\
\hline Same gender & & & & 0.20 & 0.21 & $-0.21,0.62$ & 0.23 & 0.20 & $-0.18,0.63$ \\
\hline Shared perspective & & & & $0.52 *$ & 0.20 & $0.11,0.92$ & $0.73 * * *$ & 0.21 & $0.31,1.14$ \\
\hline Trustworthy behaviors & & & & $0.45^{*}$ & 0.19 & $0.07,0.84$ & $0.42 \dagger$ & 0.22 & $0.00,0.85$ \\
\hline H1A: Same age*RL & & & & & & & -0.09 & 0.27 & $-0.63,0.45$ \\
\hline H1B: Same gender*RL & & & & & & & $-0.83^{*}$ & 0.33 & $-1.48,-0.17$ \\
\hline H2: Trustworthy behaviors*RL & & & & & & & $0.85^{* *}$ & 0.27 & $0.32,1.38$ \\
\hline $\mathrm{H} 2$ : Trustworthy behaviors* $\mathrm{RL}^{2}$ & & & & & & & $-1.00 * *$ & 0.35 & $-1.69,-0.32$ \\
\hline H3: Shared perspective* RL & & & & & & & $-0.68 *$ & 0.30 & $-1.27,-0.08$ \\
\hline
\end{tabular}

Note. $\quad N=88 . R^{2}=.09$ for Equation $1(p=.353) ; \Delta R^{2}=.29$ for Equation 1 to $2(p<.001) ; \Delta R^{2}=.12$ for Equation 2 to $3(p=.009)$, which includes $\Delta R^{2}=.05$ for H1B $(p=.014), \Delta R^{2}=.06$ for both components of $\mathrm{H} 2(p=.014)$, and $\Delta R^{2}=.07$ for $\mathrm{H} 3(p=.002)$. CI $=$ confidence interval; $\mathrm{H}=$ hypothesis; $B=$ unstandardized coefficient.

$\dagger p<.10 . * p<.05 . \quad * * p<.01 . \quad * * * p<.001$

to have a lower level of trust in a younger supervisor or older subordinate and did not appear to "get over it" even after getting to know the other person better.

\section{Discussion}

We set out to determine whether different bases of interpersonal trust matter uniquely for relationships of different lengths. Consistent with predictions derived from information-processing the-

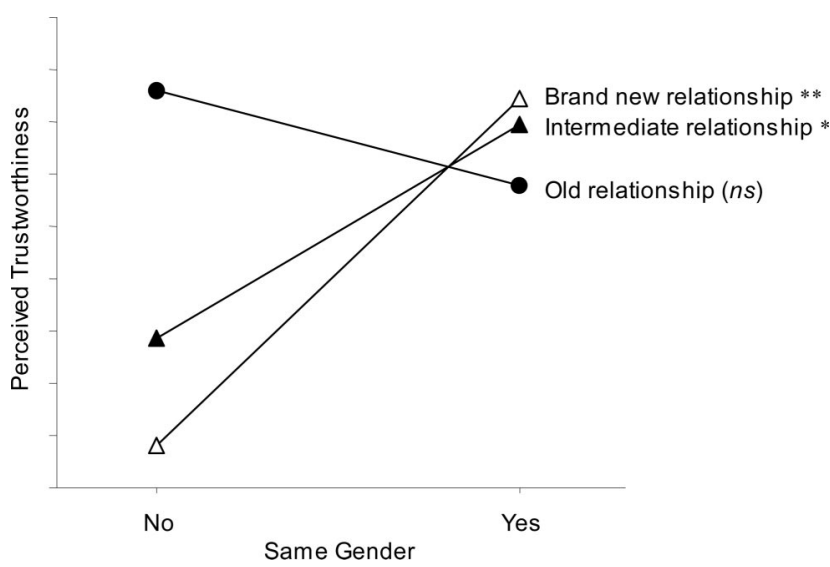

Figure 1. Interaction of same gender and relationship length, based on regression coefficients in Equation 3. Simple slopes shown are 1.33 for brand new relationships (i.e., relationships of no duration; $p=.009$ ), 0.82 for intermediate relationships (i.e., relationships of medium duration; $p=$ .014 ), and -0.36 for old relationships (i.e., relationships of high duration; $p=.222$ ). If a line's simple slope is not statistically significant here, this indicates that the true line could actually be horizontal. $* p<.05$. ${ }^{*} p<.01$. ory, we found that relationship length did not have a direct association with a person's trust in another party but rather a complex and curvilinear one. Specifically, we found that in newer relationships, the bases of trust in another party are rooted primarily in gender similarity; in intermediate relationships, in behavioral expectations from moderate social interaction; and in older relationships, in personal knowledge of shared perspectives.

Our framework is consistent with the notion that trust can begin either swiftly (McKnight et al., 1998; Meyerson et al., 1996) or

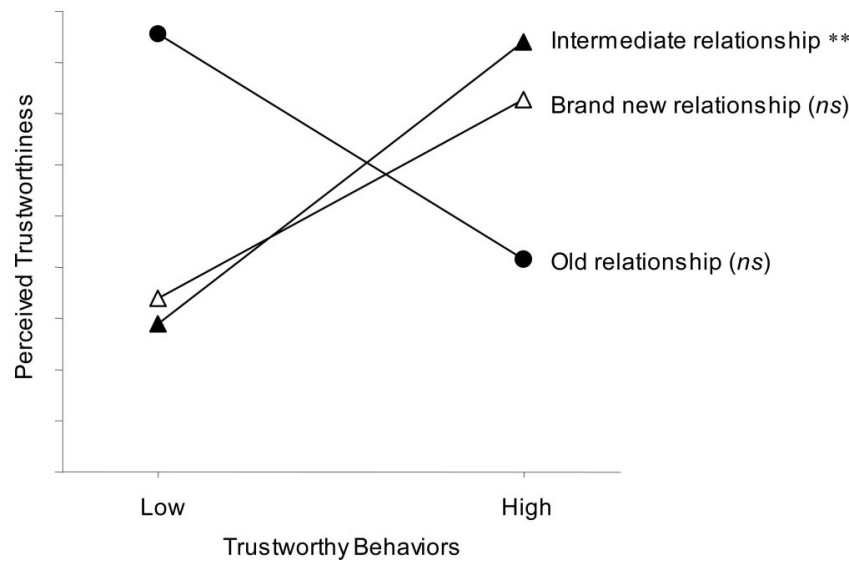

Figure 2. Interaction of trustworthy behaviors and relationship length, based on regression coefficients in Equation 3. Simple slopes shown are 0.56 for brand new relationships ( $p=.170), 0.80$ for intermediate relationships ( $p=.001$ ), and -0.64 for old relationships ( $p=.108$ ). If a line's simple slope is not statistically significant here, this indicates that the true line could actually be horizontal. $* * p<.01$. 


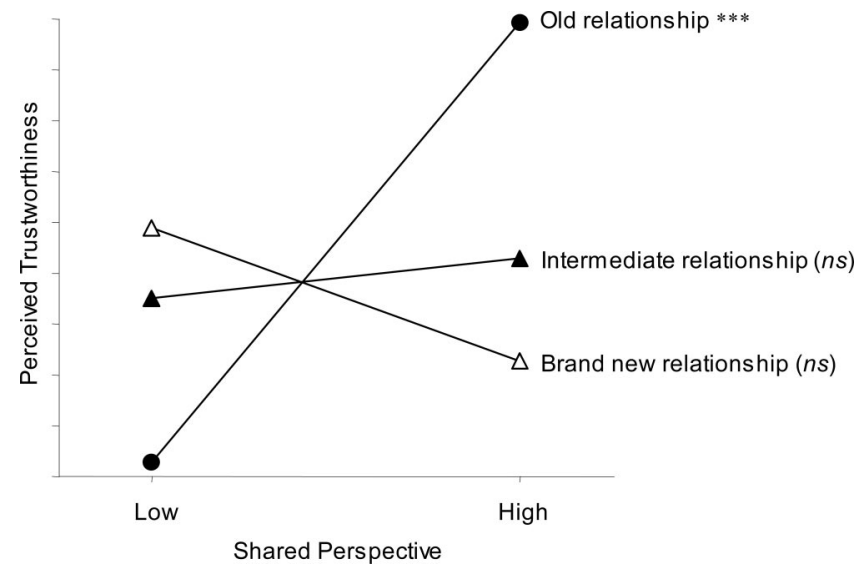

Figure 3. Interaction of shared perspective and relationship length, based on regression coefficients in Equation 3. Simple slopes shown are -0.40 for brand new relationships ( $p=.252), 0.12$ for intermediate relationships ( $p=.608)$, and 1.33 for old relationships $(p<.001)$. If a line's simple slope is not statistically significant here, this indicates that the true line could actually be horizontal. $* * * p<.001$.

slowly, and subsequently depends on which trust bases are available and what they indicate. Future research examining this issue could be combined with work on communication frequency (Becerra \& Gupta, 2003), which is likely to vary over time. We were only able to control for frequency using a static measure; however, future work might create a measure of cumulative as well as recent interaction. Indeed, we would expect even stronger results with this type of approach, as our use of mere time of acquaintance is probably the leanest proxy for relationship and therefore a more conservative test of our hypotheses. Future research might also examine how long the subordinate has reported to the supervisor. More generally, given our finding that same gender mattered but same age did not, future work should explore the possibility that demographic differences may mean different things, depending on the context or prevailing norms (Lawrence, 1988, 1996).

Although we have so far portrayed the framework as progressing only in one direction, we believe that future work should explore the possibility that a salient group prototype can resurface (Hogg \& Terry, 2000)—perhaps caused by an external shock, and absent any specific behavioral changes by either party-making even older relationships shift back to a demographic basis for trust. Many trust models acknowledge that trust building is neither inevitable nor irreversible and that trust can turn to distrust through dramatic behavioral changes by either party, such as betrayal (Jones \& George, 1998). We would predict, however, that changes in the salience of group membership can also lead to an unexpected change in the basis of trust. So, for example, a polarizing class-action sex-discrimination lawsuit might cause even seemingly unaffected long-term relationships to revert back to using prototypic categories or schemas (e.g., same gender) as a basis for trust. We consider our framework's ability to accommodate these various possibilities to be one of the strengths of our theoretical approach.

We recognize several limitations of our study. The data come from a cross-sectional sample that included relationships of dif- ferent lengths. The results suggest that the bases of trust differ over time, but longitudinal data are needed to verify this and to test whether the bases change over time and possess different consequences. A longitudinal study could address questions such as these: Do individuals in new relationships base their trust on demographic similarities or other depersonalized group prototypes and then change their expectations, and thus their base of trust, as they get to know the other person better? Are there management practices that could facilitate the shift from one base to another, helping to manage the change in expectations? Is trust more resilient when rooted in shared perspective than when rooted in demographic similarity? Another limitation is that we tested only a few constructs related to similarity and trust. This was due largely to concerns from participating companies about survey length and privacy/legal issues. Future work, however, should address other group categories, such as race and professional background (which we would expect to be more predictive of trust in newer relationships than in older ones), as well as other aspects of perceived trustworthiness, such as integrity and ability (Mayer et al., 1995). Nevertheless, we feel the current measures are a vital first step in understanding the complex role of relationship length in the decision to trust or not.

In summary, trust plays a critical role in relationships in organizations, yet predictions that individuals in older relationships are more likely to trust each other have not been supported empirically (Dirks \& Ferrin, 2002). We propose that this result is not surprising, as the direct association-as measured by the zero-order correlation-between relationship length and trust should be zero; instead, trust should be affected by the interaction of relationship length and bases of trust. The results of a survey of supervisors and subordinates support this prediction: In newer relationships, trust is associated with demographic similarity (same gender); in intermediate relationships, with observations of behavior; and in older relationships, with shared perspective.

We also feel our findings hold implications for practice. Trust is an appealing concept that has become prominent in recent practitioner-oriented publications on social capital (e.g., Abrams et

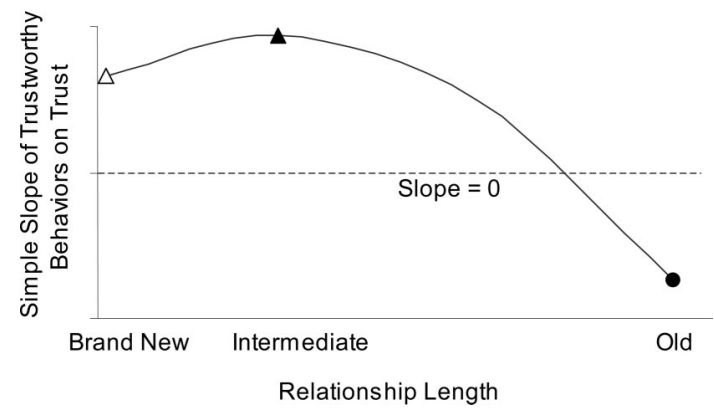

Figure 4. Interaction of trustworthy behaviors and relationship length, based on simple slopes of regression coefficients in Equation 3. As indicated by the squared-term interaction in Equation 3, the presence of an upside-down- $U$ shape is statistically significant here $(p=.026)$. Of the three marked points, which correspond to the three simple slopes shown in Figure 2, the intermediate relationship is significantly different from zero $(p=.001)$, but brand new $(p=.170)$ and old relationships $(p=.108)$ are not. 
al., 2003; Cohen \& Prusak, 2001). But it is also elusive and seemingly difficult for managers to inscribe in their organizations. Our results speak to one possible reason for this. Rather than universally apply a list of behaviors or practices to establish trust in relationships, our results suggest that measured and specific approaches need to be taken depending on the relationship's length. This holds implications for managers' own relationships, as well as for the development of trust more broadly in entire networks of relationships.

\section{References}

Abrams, L. C., Cross, R., Lesser, E., \& Levin, D. Z. (2003). Nurturing interpersonal trust in knowledge-sharing networks. Academy of Management Executive, 17(4), 64-77.

Aiken, L. S., \& West, S. G. (1991). Multiple regression: Testing and interpreting interactions. Thousand Oaks, CA: Sage.

Argyres, N. S. (1999). The impact of information technology on coordination: Evidence from the B-2 "stealth" bomber. Organization Science, 10, 162-180.

Bandura, A. (1986). Social foundations of thought and action: A social cognitive theory. Englewood Cliffs, NJ: Prentice Hall.

Becerra, M., \& Gupta, A. K. (2003). Perceived trustworthiness within the organization: The moderating impact of communication frequency on trustor and trustee effects. Organization Science, 14, 32-44.

Blau, P. M. (1964). Exchange and power in social life. New York: Wiley. Bobrow, D. G., \& Norman, D. A. (1975). Some principles of memory schemata. In D. G. Bobrow \& A. Collins (Eds.), Representation and understanding (pp. 131-149). New York: Harcourt Brace Jovanovich.

Brewer, M. B. (1979). In-group bias in the minimal intergroup situation: A cognitive-motivational analysis. Psychological Bulletin, 86, 307-324.

Brewer, M. B. (1981). Ethnocentrism and its role in interpersonal trust. In M. B. Brewer \& B. E. Collins (Eds.), Scientific inquiry and the social sciences (pp. 345-359). New York: Jossey-Bass.

Brockner, J., Siegel, P. A., Daly, J. P., Tyler, T., \& Martin, C. (1997). When trust matters: The moderating effect of outcome favorability. Administrative Science Quarterly, 42, 558-583.

Burt, R. S. (1992). Structural holes. Cambridge, MA: Harvard University Press.

Butler, J. K., Jr. (1991). Toward understanding and measuring conditions of trust: Evolution of a conditions of trust inventory. Journal of Management, 17, 643-663.

Chatman, J., \& Flynn, F. (2001). The influence of demographic heterogeneity on the emergence and consequences of cooperative norms in work teams. Academy of Management Journal, 44, 956-974.

Chattopadhyay, P. (1999). Beyond direct and symmetrical effects: The influence of demographic similarity on organizational citizenship behavior. Academy of Management Journal, 42, 273-287.

Cohen, D., \& Prusak, L. (2001). In good company: How social capital makes organizations work. Cambridge, MA: Harvard Business School Press.

Currall, S., \& Judge, T. (1995). Measuring trust between organizational boundary role persons. Organizational Behavior and Human Decision Processes, 64, 151-170.

Davis, J. H., Schoorman, F. D., Mayer, R. D., \& Tan, H. H. (2000). The trusted general manager and business unit performance: Empirical evidence of a competitive advantage. Strategic Management Journal, 21, 563-576.

Dirks, K. T., \& Ferrin, D. L. (2002). Trust in leadership: Meta-analytic findings and implications for research and practice. Journal of Applied Psychology, 87, 611-628.

Doty, H. D., \& Glick, W. H. (1998). Common methods bias: Does common methods variance really bias results? Organizational Research Methods, 1, 374-406.

Driscoll, M. P. (2005). Psychology of learning for instruction. Boston: Pearson.

Ferrin, D. L., \& Dirks, K. T. (2003). The use of rewards to increase and decrease trust: Mediating processes and differential effects. Organization Science, 14, 18-31.

Hansen, M. T. (1999). The search-transfer problem: The role of weak ties in sharing knowledge across organization subunits. Administrative Science Quarterly, 44, 82-111.

Hogg, M. A., \& Terry, D. J. (2000). Social identity and self-categorization processes in organizational contexts. Academy of Management Review, $25,121-140$.

Johnson, J. L., Cullen, J. B., Sakano, T., \& Takenouchi, H. (1996). Setting the stage for trust and strategic integration in Japanese-U.S. cooperative alliances. Journal of International Business Studies, 27, 981-1004.

Jones, G. R., \& George, J. M. (1998). The experience and evolution of trust: Implications for cooperation and teamwork. Academy of Management Review, 23, 531-546.

Kim, P. H., Ferrin, D. L., Cooper, C. D., \& Dirks, K. T. (2004). Removing the shadow of suspicion: The effects of apology versus denial for repairing competence- versus integrity-based trust violations. Journal of Applied Psychology, 89, 104-118.

Korsgaard, M. A., Brodt, S. E., \& Whitener, E. M. (2002). Trust in the face of conflict: Role of managerial trustworthy behavior and organizational context. Journal of Applied Psychology, 87, 312-319.

Lawrence, B. S. (1988). New wrinkles in the theory of age: Demography, norms, and performance ratings. Academy of Management Journal, 31, 309-337.

Lawrence, B. S. (1996). Organizational age norms: Why is it so hard to know one when you see one? Gerontologist, 36, 209-220.

Levin, D. Z., \& Cross, R. (2004). The strength of weak ties you can trust: The mediating role of trust in effective knowledge transfer. Management Science, 50, 1477-1490.

Lewicki, R. J., \& Bunker, B. B. (1996). Developing and maintaining trust in work relationships. In R. M. Kramer \& T. R. Tyler (Eds.), Trust in organizations: Frontiers of theory and research (pp. 114-139). Thousand Oaks, CA: Sage.

Mayer, R. C., Davis, J. H., \& Schoorman, F. D. (1995). An integration model of organizational trust. Academy of Management Review, 20, 709-734.

McAllister, D. J. (1995). Affect- and cognition-based trust as foundations for interpersonal cooperation in organizations. Academy of Management Journal, 38, 24-59.

McKnight, D. H., Cummings, L. L., \& Chervany, N. L. (1998). Initial trust formation in new organizational relationships. Academy of Management Review, 23, 473-490.

Meyerson, D., Weick, K. E., \& Kramer, R. M. (1996). Swift trust and temporary groups. In R. M. Kramer \& T. R. Tyler (Eds.), Trust in organizations: Frontiers of theory and research (pp. 166-195). Thousand Oaks, CA: Sage.

Morrison, E. W. (2002). Newcomers' relationships: The role of social network ties during socialization. Academy of Management Journal, 45, $1149-1160$.

Neath, I. (1998). Human memory. Pacific Grove, CA: Brooks/Cole.

Neter, J., Kutner, M. H., Nachtschiem, C. J., \& Wasserman, W. (1996). Applied linear statistical models (4th ed.). Chicago: Irwin.

Podsakoff, P. M., MacKenzie, S. B., Lee, J., \& Podsakoff, N. P. (2003). Common method biases in behavioral research: A critical review of the literature and recommended remedies. Journal of Applied Psychology, 88, 879-903.

Reicher, G. M. (1969). Perceptual recognition as a function of meaning- 
fulness of stimulus material. Journal of Experimental Psychology, 81, 274-280.

Rousseau, D. M., Sitkin, S. B., Burt, R. S., \& Camerer, C. (1998). Not so different after all: A cross-discipline view of trust. Academy of Management Review, 23, 393-404.

Rumelhart, D. E. (1984). Schemata and the cognitive system. In R. S. Wyer \& T. R. Srull (Eds.), Handbook of social cognition (Vol. 1, pp. 161187). Hillsdale, NJ: Erlbaum.

Rumelhart, D. E., \& McClelland, J. L. (1981). An interactive activation model of context effects in letter perception: Pt. 1. An account of basic findings. Psychological Review, 88, 375-406.

Scott, J. (1990). Social network analysis. Thousand Oaks, CA: Sage.

Shore, L. M., Cleveland, J. N., \& Goldberg, C. B. (2003). Work attitudes and decisions as a function of manager age and employee age. Journal of Applied Psychology, 88, 529-537.

Simons, T. (2002). Behavioral integrity: The perceived alignment between managers' words and deeds as a research focus. Organization Science, $13,18-35$.
Sitkin, S. B., \& Roth, N. L. (1993). Explaining the limited effectiveness of legalistic "remedies" for trust/distrust. Organization Science, 4, 367392.

Tsai, W., \& Ghoshal, S. (1998). Social capital and value creation: The role of intrafirm networks. Academy of Management Journal, 41, 464-476.

Tsui, A. S., \& O'Reilly, III, C. A. (1989). Beyond simple demographic effects: The importance of relational demography in superiorsubordinate dyads. Academy of Management Journal, 32, 402-423.

Whitener, E., Brodt, S., Korsgaard, A., \& Werner, J. (1998). Managers as initiators of trust: An exchange relationship framework for understanding managerial trustworthy behavior. Academy of Management Review, $23,513-530$.

Received May 12, 2004

Revision received June 24, 2005

Accepted July 5, 2005 